International Journal of Linguistics, Literature and Translation

ISSN: 2617-0299 (Online); ISSN: 2708-0099 (Print)

DOI: 10.32996/ijltt

Journal Homepage: www.al-kindipublisher.com/index.php/ijltt

IJLLT

\title{
The Relationship between Self-esteem and Reading Motivation: Moroccan EFL University Students as a Case Study
}

\author{
Abdelouahed Bouih ${ }^{1} 8$ (D) $\triangle$, Driss Benattabou 2 8(D) \\ ${ }^{1}$ Ph.D. Student, English Department, Moulay Ismail University, Meknes, Morocco \\ ${ }_{2}^{2}$ Full Professor, English Department, Moulay Ismail University, Meknes, Morocco \\ $\triangle$ Corresponding Author: Abdelouahed Bouih, E-mail: Abdelouahed.bouih@gmail.com
}

\author{
ARTICLE INFORMATION \\ Received: February 04, 2021 \\ Accepted: March 05, 2021 \\ Volume: 4 \\ Issue: 3 \\ DOI: $10.32996 /$ ijllt.2021.4.3.5
}

\section{KEYWORDS}

Self-esteem, Reading Motivation, Gender, correlation, group comparison, direct effect

\section{ABSTRACT}

This study aims primarily to investigate the relationship between Self-esteem (SE) and Reading Motivation (RM) among EFL university students in Morocco. Another aim of this research is to examine the role of gender in shaping this relationship. A questionnaire on $\mathrm{SE}, \mathrm{RM}$ and socio-biographical data was completed by one hundred and eighty $(N=180)$ participants of undergraduate and graduate levels. Bivariate statistical analyses showed low significant correlational results using standardized summed scores of SE and RM. Moderately significant results have been observed based on SE and RM factors extracted using Principal Component Analysis (PCA) after both constructs were shown to have acceptable internal consistency. Using structural equation modeling (SEM), we evaluated a direct effect measurement model to investigate the unidirectional impact of SE on RM and its concordance with the structural model. Corresponding results revealed acceptable goodness-of-fit indexes indicating the validity of the structural model and demonstrating a positive effect of $\mathrm{SE}$ on RM. The examination of gender-based scores showed that there was no significant difference between males and females both in SE and RM.

\section{Introduction}

The self is at the heart of cognitive processes that links underlying motives to action with the intent of achieving specific goals. It is also seen as underlying the functional instigators that trigger specific behavioral outcomes (Cantor et al., 1986). The self is also defined as an integrated, dynamic and out-flowing multi-dimensional jointure that manifests itself in various forms (e.g. selfconcept and self-esteem) and at various levels (e.g. socially and linguistically) (Baumeister, 1999a), and purports to yield itself not only to abstract conceptualization but also to theoretical construct operationalization and real-world quantifiable statistical measurement.

On the premise that reading behavior is a form of motivation-based action (Aarnoutse \& Schellings, 2003) and that reading motivation is a domain-specific approach to motivation (Wigfield, 1997), various dimensions of the self can a priori be rightly assumed to be relationally commensurate with the various goal-directed motivated actions. Hitherto, faced with a rich plethora of diverse language-related phenomena, the obligation of choice compels us to a fastidious selection of one aspect of the self, namely self-esteem, and one domain-specific motivation, namely reading motivation.

Because the relationship between these two specific variables, self-esteem and reading motivation, has not been enthusiastically explored as other forms of self-relevant constructs in combination with motivated language behavior (e.g. Apriliyanti et al., 2018; Arens \& Jansen, 2016; Van Lier, 2010; Boonchum, 2009), we judge it to be a potentially fruitful endeavor and a very promising area of research still in dire need of more investigations.

The present study sets out to examine an uncharted area of research, namely the interconnected relationship between selfesteem and reading motivation among a group of university students studying English as a foreign language in the Moroccan

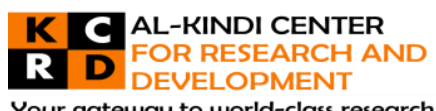

Your gateway to world-class research

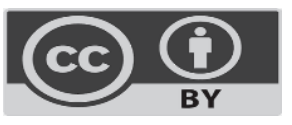

Published by Al-Kindi Center for Research and Development. Copyright (c) the author(s). This open access article is distributed under a Creative Commons Attribution (CC-BY) 4.0 license 
context using standard correlational tests and SEM techniques by investigating respectively the correlational link and the unidirectional effect between the two constructs using a moderate size convenience sample. The structure of the paper is divided into two parts along with an introduction and a conclusion. The first part constitutes a theoretical framework which provides a set of conceptual definitions for both self-esteem and reading motivation, and goes afterwards to discuss each construct in relation to language learning. Attempts shall be made also to examine the way this relationship between self-esteem and reading motivation is shaped by the role of gender. This part is also concerned with reviewing the literature regarding the relationship between self-esteem and reading motivation. The second part of the study is more analytical as it attempts to explore whether there is a relationship between self-esteem and reading motivation. The paper ends up with a conclusion highlighting important findings and making recommendations for future research.

\section{Literature Review}

\subsection{Self-esteem}

Self-esteem falls into the category of affective variables, in contrast to cognitive variables, along with such major constructs as motivation, attitude, empathy and anxiety (Dörnyei\& Ryan,2015) to name but only a few. Self-esteem is one of the most researched variables in psychology (Cast \& Burke, 2002) although it is less so in language-related research in particular (Dörnyei\& Ryan, 2015).

Self-esteem has been conceptualized in different ways by different researchers as the definitions range from less complex to more subtle ones. Robson (1989) defines self-esteem as being "the sense of contentment and self-acceptance that results from a person's appraisal of his own worth, significance, attractiveness, competence, and ability to satisfy his aspirations" (p. 514). Similarly, a more general definition was proposed by Baumeister (1998) as he describes self-esteem as "the positivity of the person's self-evaluation" (p.694). Self-esteem was likewise conceived of as a "subjective self-evaluation that is not necessarily based on any specific behaviors." (Robins et al., 2001, p. 152). The concept of self-esteem has equally been defined as "what one thinks and feels about one self generally" (Dörnye et al., 2014, p. 141) while perhaps a more appealing definition that yields itself to evaluation is that of "a personal judgment of worth lying along a dimension with " 'positive' and 'negative' end." (Lawrence, 1981, p. 245).

More intuitively, global self-esteem is considered as "an individual's evaluation of his overall worth as a person" (Simpson \& Boyle, 1975). This definition seems to yield itself a priori to practical and useful operationalization for instrument design. Although self-esteem shares commonalities and tends to overlap with constructs such as optimism, self-worth, self-mastery (Scheier et al., 1994), self-confidence, self-efficacy (Dörnyei \& Ryan, 2015), self-image (Rosenberg, 1965), and that some of these constructs are sometimes conceived of to be aspects of the self (Baumeister, 1999b) and a component of it (Zaff \& Hair, 2003), self-esteem has a long history that dates back at least to the 1960's (Coopersmith, 1968)corroborating its originality and distinctiveness vis-à-vis similar constructs.

\subsection{Self-esteem, language learning and gender differences}

The pursuit of self-esteem research is an important, fruitful and a consequential line of inquiry (DuBois \& Flay, 2004; Swann et al., 2007) despite the criticism that may sometimes reveal to be inadequate, severe and unconstructive and that may give the appearance to be detrimental (e.g. Crocker \& Park, 2004;Baumeisteret al., 2005).Those reasons are essentially a reflection of the fact that self-esteem is associated to learning and to a wide range of learning variables such as learning strategies (MartínAlboetal.,2007), self-efficacy (Afari et al.,2012), ESL oral production (Heyde, 1979), listening comprehension (Hayati, \& Ostadian, 2008), learning style and reading motivation (Abouserie, 1995), personality variables (Robins et al., 2001), and ESL level proficiency (Soureshjani \& Naseri, 2011).

Evidence shows that self-esteem correlates with academic performance (Simpson \& Boyle, 1975). In fact, self-esteem was found to be associated to academic achievement (Trautweinetal.,2006; Alves-Martins et al., 2002) past academic performance (Lane et al., 2004), and educational achievement in general (Booth \& Gerard, 2011) in addition to being a contributing factor to it (Baumeister et al.,2003;Maqsud,1983; Soufi et al.,2014) - albeit not substantially as there are somewhat contradictory evidence and arguments from both sides-while in contrast, a more nuanced conception holds that self-esteem is not directly linked to academic achievement as much as low self-esteem is linked to academic problems and underachievement (Di Giunta et al., 2013).

In relation to the learning process, it has been argued that successful learning is very difficult to occur if at all in the absence or at least the quasi-absence of a good positive view of the self as measured through variables such as self-esteem and selfconfidence (Brown, 2006). This applies in principle to both males and females. Incidentally, evidence shows that males appear to have higher self-esteem (Srivastava \& Joshi, 2014; Bagley et al., 1997) while other studies emphasize that self-esteem differences between both genders are not significant (Kling et al., 1999). An examination of the relevant literature, however, consisting in part of an abundance of evidence which shows that males tend to report consistently higher self-esteem compared to females 
(e.g. Kling et al., 1999; Gentile et al., 2009; McMullin \& Cairney, 2004; Stein et al.,1992; Chubb et al.,1997; AlKhatib, 2012). In fact, multiple studies have further confirmed this observation across cultures and age brackets (Bleidorn et al., 2016).

\subsection{Reading motivation}

As a learned practice and a language skill, reading has been an interest for both theorists and practitioners (Watkins \& Coffey, 2004). Reading comprises the ability to decode words with accuracy as well as the ability to gain meaning from it (Berkeley et al., 2010). Reading is a motivated behavior (Aarnoutse \& Schellings, 2003) and reading motivation demonstrates a specific interest for reading (Guthrie et al., 2006) that activates reading behavior (Aarnoutse \& Schellings, 2003). Definitions of reading motivation generally converge as they describe conceptually one phenomenon- in spite of the fact that there is a lack of clarity in terms of motivational constructs definition, which often creates confusion between terms (Frijters et al., 2019; Conradi et al., 2014; Schiefele et al., 2012).

To further illustrate this, researchers like Guthrie \& Wigfield (1999) define reading motivation as "the individual's goals and beliefs with regard to reading" (p. 199), while Schiefele et al.,(2012) describe it as referring to intentions behind and reasons for reading. Moreover, Unrau \& Quirk (2014)state that reading motivation consists of the "internal processes that instigate and sustain reading activity" (p. 272) and view it as "the thoughts, beliefs, and self-perceptions that provide the impetus for a person to engage in or sustain reading-related activities" (p. 272).In this context, a more elaborated and consensual definition was reported by Conradi et al.,(2014) whereby reading motivation embodies "The drive to read resulting from a comprehensive set of an individual's beliefs about, attitudes toward, and goals for reading" (p. 154), in addition to its constituent sub-constructs including intrinsic and extrinsic reading motivation representing respectively "the drive to read for internal purposes, such as deriving pleasure, attaining personal goals, or satisfying curiosity" (p. 154)and "the drive to read for external purposes, such as rewards or recognition" (p. 154).

There is a wide variety of types of reading from Academic Reading (AR), to Internet Reading (IR) to Extracurricular Reading (ER) also called Recreational Reading (RR) (Huang et al., 2014) among others, all fitting a priori into fiction or non-fiction categories. Reading has various sources ranging from magazines to books (Gabriel et al., 2012) to various reading materials including newspapers and Manga (Chen, 2007). Reading is not restricted to one's field of interest and to in-school reading or to specific books and genres outside their field of study (e.g. Shankar et al., 2008). Underlying the consumption of these various forms and genres of reading materials is the cognitive deliberate and motivated process that purports to be measured by the construct of reading motivation.

\subsection{Reading motivation, language learning, and gender differences}

Research shows that reading motivation is linked to various reading-related constructs. Classically, as mentioned previously, reading motivation has been operationalized through both sub-constructs of intrinsic and extrinsic motivation. Intrinsic reading motivation reflects internal factors such as curiosity while extrinsic reading motivation is associated to external factors such as grade (McGeown et al., 2012). In terms of language performance, one longitudinal study for instance concluded that both intrinsic and extrinsic reading motivation predict reading literacy (Becker et al., 2010), which in turn predicts "receptive vocabulary, general information, spelling, sight vocabulary, verbal fluency, and reading comprehension even after controlling for age, recognition memory" (Echols et al.,1996, p. 296).

Further, similar findings revealed that reading motivation predicts word reading, summarization and text reading speed as well as comprehension (McGeown et al., 2015) in addition to being associated to the enjoyment of reading and reading patterns (Schutte \& Malouff, 2007), reading achievement (Hebbecker et al.,2019), reading comprehension (Wang \&Guthrie, 2004) and growth in reading comprehension (Guthrie et al. , 2007). In a related study, it has also been found that dimensions of reading motivation predict variance in reading skills (McGeown et al.,2015) and that these in consequence predict reading habits (Leppänen et al.,2005) which were found to correlate positively with an increase in comprehension and vocabulary (Kammann, 1963).

In terms of gender-based reading motivation differences, numerous findings report that males and females show no difference in extrinsic reading motivation while females on the other hand show higher intrinsic reading motivation than their male counterparts (McGeown et al.,2012; Stutz et al.,2016).In the same vein, evidence shows that masculine and feminine traits respectively predicted in part reader's sex, the analysis of which indicated that feminine traits are more associated to reading motivation (McGeown, 2015). Upon the examination of numerous sources, there seems to be a persistent reading motivation advantage associated to females over males in both children and adolescents (Schwabe et al.,2015; McGeown et al., 2015) as females demonstrate more motivation to read than males do (Wigfield et al.,2016; Pecjak \& Peklaj, 2006); they demonstrate more stability in reading attitude (Kush, \& Watkins, 1996); they enjoy reading more than males (Merisuo-Storm, 2006); and they are more likely to describe themselves as enthusiastic readers (Twist et al., 2004). In a similar fashion, research affirms that 
women tend to show higher intrinsic reading motivation scores as studies with a focus on adults show that gender disparities in reading motivation during childhood persist through adulthood as well (Frijters et al., 2019).

Despite the availability of evidence in the subject matter and all the resources made at the disposal of the researchers, research in reading motivation has classically focused mainly on children and adolescents but to a substantially lesser extent on adults. In an important review of the reading motivation literature, Conradi et al. (2014) reported that only seven percent of the target population were adults in studies involving reading motivation between 2003 and 2014. This calls for more research efforts to be deployed in this area of adult reading motivation particularly in underexplored contexts like Morocco.

\subsection{Self-esteem and reading motivation}

In spite of the fact that the relationship between self-esteem and reading motivation has seldom been directly studied and given the little evidence for it particularly using adult population, which is in our estimation a structural gap, the indirect link between the two constructs has nevertheless been established. Descriptively, self-esteem is one of the reasons that motivate children to read (Baker \& Scher, 2002) entailing logically a relationship linking both phenomena. In a similar context, using a sample of school children, a set of factors including self-esteem helped create an environment conducive to motivate children to read resulting in a positive outcome (Harrison, 1994). One more study using a sample of middle school students demonstrates in the same way a positive relationship between self-esteem and motivation to read, and that students with positive self-esteem are motivated to try to read if they identify themselves as poor readers (Hisken, 2011). This testifies to the unidirectional link between self-esteem and reading motivation. In fact, not only the relationship has been posited to be unidirectional, which was demonstrated to be true, but it has also been argued that there is a reciprocal relationship between reading self-esteem and a positive attitude towards reading (Kaniuka, 2010).

However, once again, in so far as the current literature review goes, there is little evidence that the relationship between selfesteem and reading motivation relationship has been studied directly albeit an indirect link has long been shown in numerous contexts, as research pointed out that self-esteem correlates with reading achievement (Booth \& Gerard, 2011) and performance (Carretal.,1991) as reading achievement correlates with reading motivation (Baker \& Wigfield, 1999; Forster \& Souvignier, 2014; Pecjak \& Peklaj, 2006).

The purpose of the current study is to explore the direct relationship between self-esteem and reading motivation both at the correlational level and at the level of the direct effect of self-esteem on reading motivation, in addition to examining whether gender accounts for any significant difference in terms of the scores of a sample of male and female Moroccan students at the university level.

\section{Methodology}

\subsection{The hypotheses}

In the light of the prevailing arguments pertaining to the literature reviewed earlier, one may postulate four different but interconnected research hypotheses:

(1) There is a positive correlation between self-esteem and reading motivation.

(2) There is a significant difference between men and women in reported self-esteem level.

(3) There is a significant difference between men and women in reported reading motivation scores.

(4) There is a significant direct effect of self-esteem on reading motivation.

\subsection{Participants and data collection procedures}

The population is represented by a non-random convenience sample composed of 112 (62\%) male students and 68 (38\%) female students of a total of 180 participants. The most frequent age bracket is 20-25 years old making nearly (36\%), followed by 25-30 years old making approximately (27\%) of the sample, while 30-35 years old participants make up (18\%). 35-40 years old participants make up (12\%) and the remaining (7\%) is represented by $40-45$ years old ones. The most frequent diploma reported is the B.A. representing 72 participants roughly (40\%) when 59 (33\%) reported having a Master's degree. The remaining 49 participants (27\%) reported having a two-year diploma.The sampled participants were drawn from multiple universities including Moulay Ismail University in Meknes, Moulay Slimane University in Beni Mellal, Ibn Tofail University in Kenitra, and Mohammed V University in Rabat. Participants completed the computerized self-esteem and reading motivation questionnaires by the end of the 2020 school year based on a pre-selected enrolled class students list from the various faculties as the inability of in-class administration was due to the Corona-virus-imposed restrictions. Data was stored, retrieved and processed through Microsoft Excel (2007) and SPSS (25) while tables were prepared using both Microsoft Excel and Word 


\subsection{The research instruments}

\subsection{Self-esteem}

The Rosenberg Self-esteem scale (RSE) is an economic and easy-to-administer questionnaire that consists of ten items, five of which are worded positively while the other five are worded negatively (Rosenberg, 1965). Researchers encourage the use of the RSES for measuring and assessing self-esteem in the context of higher education (Martín-Albo et al., 2007). The RSE has demonstrated good reliability and validity (Rosenberg, 1965; Scheier et al., 1994) in addition to being a commonly used measurement tool (Rubio, 2014). The RSES items range from "strongly disagree" to "strongly agree" on a five-point Likert scale.

\subsubsection{Reading motivation}

The ARMS is a twenty-one-item five-point Likert scale with positively and negatively oriented statements, and according to Schutte \& Malouff (2007), it has shown good reliability and validity. The scale ranges from "strongly disagree" to "strongly agree". As its name indicates, the Adult Reading Motivation Scale has been conceived and validated for and using adult participants, in contrast with the majority of reading scales. For this, it is considered suitable for our research context and purposes.

\section{Results}

We analyzed the dataset in search for missing data, conducted univariate outlier identification, and then performed univariate normality tests. The next step was correlational analysis of self-esteem and reading motivation before we conducted internal consistency as a verificational step to extract a corresponding factor for each construct through PCA to then re-perform correlational testing. Once the correlational analyses are performed, we constructed and evaluated a model of the direct effect link between self-esteem and reading motivation. Finally, an independent t-test for both self-esteem and reading motivation was done to reveal any potential difference between the two genders in both self-esteem level and reading motivation level.

\subsection{Data preparation and normality}

Following the order we set, our dataset showed no missing data. Data were assessed for univariate outliers using a z-score cutoff of \pm 3.29 for univariate screening (Tabachnick \& Fidell, 2013). No outliers were identified. As for univariate normality, our analysis showed that self-esteem data is normally distributed $(\mathrm{W}(180)=.986, \mathrm{p}=0.075)$ according to the Shapiro-Wilk normality test. Likewise, reading motivation was found to follow a normal distribution pattern $(\mathrm{W}(180)=.988, \mathrm{p}=0.150) \mathrm{using}$ the same test.

\subsection{Correlational analyses}

With regard to correlational analyses, the result of the Spearman correlation coefficient test between self-esteem and reading motivation was rather modestly significant $(r(178)=.16, p<.05)$ based on standardized summed scores. Likewise, using the Spearman correlational test, self-esteem correlated moderately with age (rs $(178)=.16, \mathrm{p}<.05)$ and educational level $(\mathrm{rs}(178)=$ $.22, p<.05)$, while reading motivation correlated only with age ( $r s(178)=.24, p<.001)$ (See Table 1.1).

Table 1.1 Self-esteem, reading motivation and key socio-biographical variables. Spearman correlation and descriptive statistics $(\mathrm{N}=180)$

\begin{tabular}{|c|c|c|c|c|c|c|c|c|}
\hline & Variables & 1 & 2 & 3 & 4 & 5 & $M$ & $S D$ \\
\hline 1 & Self-esteem & - & & & & & 3.60 & .56 \\
\hline 3 & Gendera & -.08 & -.10 & - & & & - & - \\
\hline 5 & Educational levelc & $.22^{*}$ & .02 & -.07 & $.29 * *$ & - & - & - \\
\hline
\end{tabular}

Gendera: 0 = male, 1 = female. Age b: $1=20-25,2=25-30,3=30-35,4=35-40,5=40-45$

Educational levelc: 1 = two-year degree, 2 = B.A., 3 = Master's degree

${ }^{*} \mathrm{p}<.05 .{ }^{* *} \mathrm{p}<.01$.

\subsection{Internal consistency, component extraction, and correlational analysis}

Both self-esteem and reading motivation scales showed good internal consistency (Self-esteem: .76; Reading motivation: .78). One factor was extracted for each scale through Principal Component Analysis (PCA). Then, the result of the Pearson 
correlational test between the factors of self-esteem and reading motivation was found to be moderately significant $(r$ (178) $=$ $.23, p<.001$ ) (See Table 1.2). Compared to the former correlational result, there appears to be a minor positive difference.

When the Spearman correlational test was rerun, results show in a similar way that self-esteem factor correlated with age (rs $(178)=.16, p<.05)$ and educational level ( $r s(178)=.22, p<.05)$, as reading motivation correlated with age $(r s(178)=.28, p<$ $.001)$.

Table 1.2 Self-esteem factor, reading motivation factor and key socio-biographical variables. Spearman correlation and descriptive statistics $(\mathrm{N}=180)$

\begin{tabular}{|c|c|c|c|c|c|c|}
\hline & Variables & 1 & 2 & 3 & 4 & 5 \\
\hline 1 & Self-esteem-factor & - & & & & \\
\hline 2 & Reading-motivation-factor & $.23 * *$ & - & & & \\
\hline 3 & Gendera & -.07 & -.11 & - & & \\
\hline 4 & Ageb & $.16^{\star}$ & $.28^{* *}$ & $-.32^{\star *}$ & - & \\
\hline 5 & Educational levelc & $.22^{* *}$ & .091 & -.07 & $-.29 * *$ & 一 \\
\hline
\end{tabular}

Gendera: 0 = male, 1 = female. Age b: $1=20-25,2=25-30,3=30-35,4=35-40,5=40-45$

Educational levelc: 1 = two-year degree, 2 = BA, 3 = Master's degree

${ }^{*} p<.05 .{ }^{* *} p<.01$.

\subsection{Direct effect of self-esteem on reading motivation}

Furthermore, we examined the effect of self-esteem on reading motivation through a direct effect model (Fig. 1). The results $X 2$ $(425)=688.028, \mathrm{p}=.000, \mathrm{CFI}=.807, \mathrm{TLI}=.788, \mathrm{RMSEA}=.059, \mathrm{SRMR}=.0844$ (Table 1.3) of the statistical model indicate a significant impact of self-esteem on reading motivation (Fig .2). The corresponding effect obtained is $\beta=.301$, $p=.002$, with a coefficient of $B=.283$ (See Table 1.4).

Figure 1

Conceptual path diagram of the effect of Self-esteem on Reading motivation

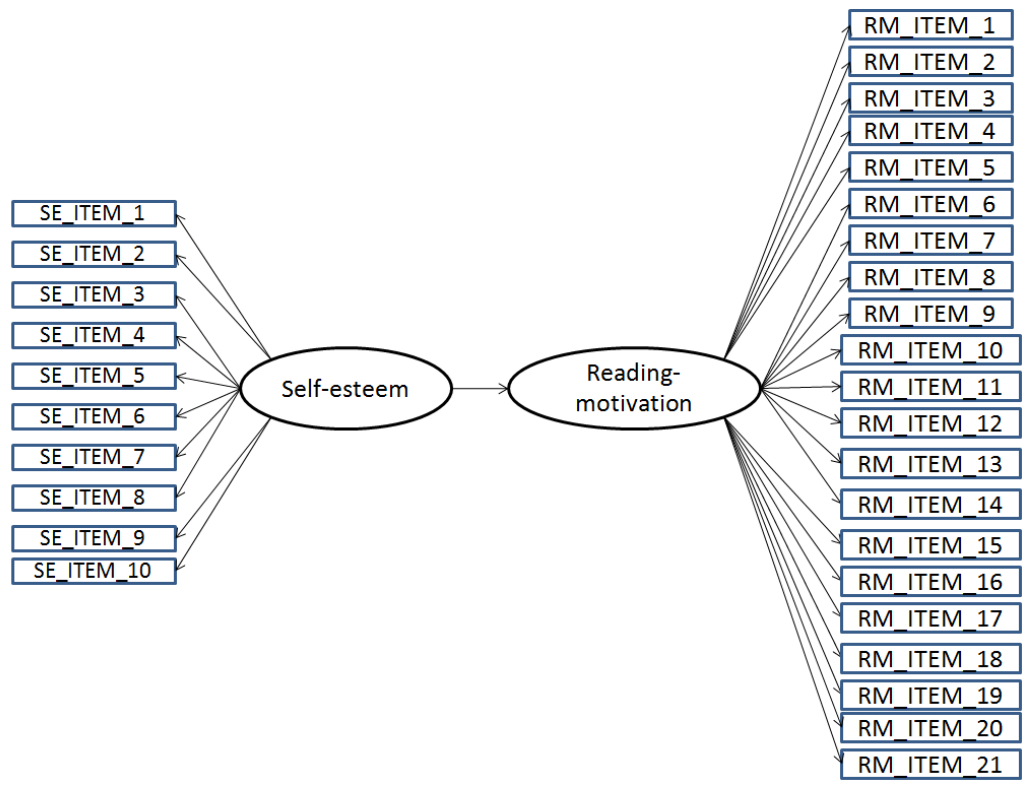


Figure 2

Statistical path diagram of the effect of Self-esteem on Reading motivation

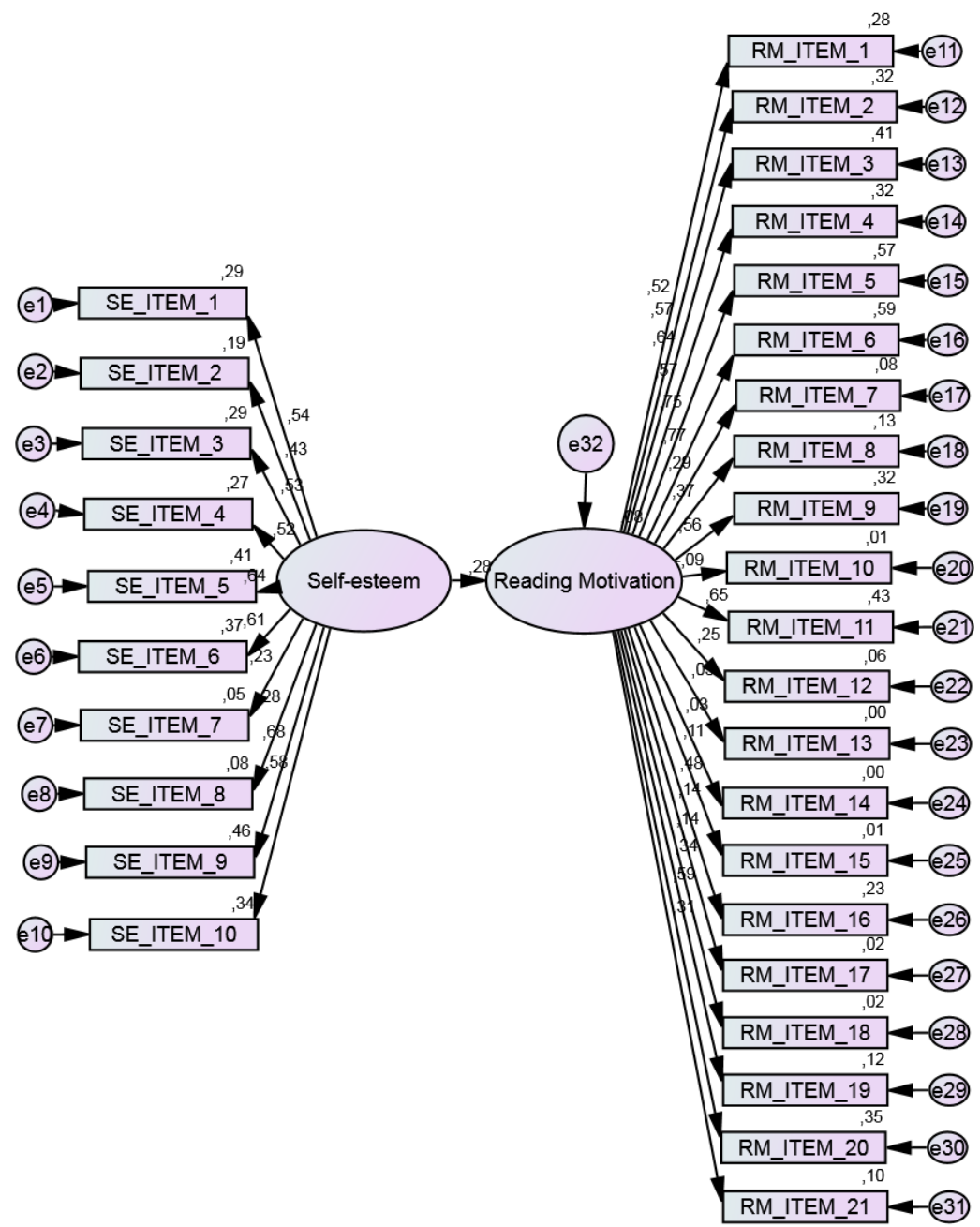

Table 1.3 Goodness-of-fit indexes of the direct effect of self-esteem on reading motivation model.

\begin{tabular}{rcccccccc}
\hline Model & $\mathbf{X}$ & $\mathbf{P}$ & $\mathbf{d f}$ & $\mathbf{X} \mathbf{2} \mathbf{d f}$ & $\mathbf{C F I}$ & $\mathbf{T L I}$ & SRMR & RMSEA \\
\hline Direct effect model & 688.028 & .000 & 425 & 1.61 & .807 & .788 & .0844 & .059 \\
\hline
\end{tabular}

Note. $\mathrm{N}=180$.

$\chi^{2}=$ chi-square goodness of fit statistic; $d f=$ degrees of freedom;

RMSEA = root mean square error of approximation; $C F I=$ Comparative Fit Index;

$\mathrm{TLI}=$ Tucker-Lewis Index; SRMR = standardized root mean square residual.

Table 1.4 Path analysis results of the direct effect of self-esteem reading motivation

\begin{tabular}{|c|c|c|c|c|c|c|c|}
\hline \multicolumn{3}{|c|}{ Effect } & \multirow{2}{*}{$\frac{\beta}{.301}$} & \multirow{2}{*}{$\frac{\beta}{.283}$} & \multirow{2}{*}{$\begin{array}{l}\text { S.E. } \\
.097\end{array}$} & \multirow{2}{*}{$\frac{C . R .}{3,100}$} & \multirow{2}{*}{$\frac{P}{.002}$} \\
\hline Self-esteem & $-->$ & Reading motivation & & & & & \\
\hline
\end{tabular}

S.E: Standard error; C.R.: Critical value; $\beta=$ unstandardized estimate; $\beta=$ standardized estimate. 


\subsection{Self-esteem on reading motivation: Group comparison}

An independent sample t-test was conducted in order to assess the difference between the two sex groups. The results show no significant difference between men and women, neither in self-esteem $t(178)=1.44, p=.152$ nor in reading motivation $t(178)=$ 1.51, $p=.122$ (See Table 1.5).

Table 1.5 Independent $t$-test results of comparison between men and women in self-esteem and reading motivation scores

\begin{tabular}{|c|c|c|c|c|c|c|}
\hline \multirow[t]{2}{*}{ Variables } & \multicolumn{2}{|c|}{$\begin{array}{c}\text { Men } \\
(n=112)\end{array}$} & \multicolumn{2}{|c|}{$\begin{array}{c}\text { Women } \\
(n=68)\end{array}$} & \multirow[b]{2}{*}{$t$} & \multirow[b]{2}{*}{$\mathrm{p}$} \\
\hline & $M$ & SD & $M$ & SD & & \\
\hline Self-esteem & 3.65 & 0.57 & 3.52 & 0.54 & 1.44 & .152 \\
\hline Reading-motivation & 3.21 & 0.44 & 3.22 & 0.45 & 1.51 & .122 \\
\hline
\end{tabular}

\section{Discussion}

\subsection{Data preparation and normality testing}

Standard scores for self-esteem and reading motivation were then calculated. Self-esteem and reading motivation are two independent variables that follow a normal distribution after data cleaning. Both self-esteem and reading motivation respectively followed a normal distribution pattern $(\mathrm{W}(180)=.986, \mathrm{p}=.075 ; \mathrm{W}(180)=.988, \mathrm{p}=.150)$ using the Shapiro-Wilk test. From this point on and having prepared data, we can safely proceed to corresponding statistical testing.

\subsection{Correlational analyses, internal consistency and factor extraction}

In terms of correlation, using the Pearson test, results $(r(178)=.16, p<.05)$ show a low significant correlation between selfesteem and reading motivation based on standardized scores. The alternative method was to extract a factor that each best represents self-esteem and reading motivation scores. Prior to this step, we checked the consistency of the respective scale items (SE: .76; RM: .78). Then we proceeded to use PCA-extracted factors in the correlational test, whose coefficient turned out to be moderately significant $(r(178)=.25, p<.05)$.

In comparison with the results previously reported in the literature, there seems to be a noticeable continuity in the sense that there is a link between self-esteem and reading motivation among adults just as it is the case with children and adolescents. The addition of the current study is that reading motivation was measured with a well pre-defined construct using an adequate tool dedicated to adults. The correlation between the two constructs generated a low significant value accounting for 2.5 percent of the variance using standardized scores and 6.2 percent of the variance using PCA extracted factors.

Numerous findings in the review of the literature (e.g. Kaniuka, 2010; Hisken, 2011) have shown that there is an indirect link between self-esteem and reading motivation. Our results however take this conclusion further by showing that there is in fact according to our data a direct correlational link between the two constructs in two different ways. We can thus confirm $\mathrm{H} 1$ hypothesizing the existence of a positive correlation between self-esteem and reading motivation.

\subsection{Direct effect of Self-esteem on reading motivation}

Furthermore, a structural equation model examining the direct effect of self-esteem on reading motivation was constructed and evaluated using fit indexes $\chi^{2}(425)=688.028, p=.000, C F I=.807, T L I=.788, R M S E A=.059, S R M R=.0844$. Utilizing the guideline and evaluation criteria of Brown (2015), model fit indices and their criteria were used to examine the goodness-of-fit of the model including the Tucker-Lewis Index (TLI; Tucker \& Lewis, 1973), comparative fit index (CFI; Bentler, 1990), standardized root mean residual (SRMR), and root mean square error of approximation (RMSEA).

On the whole, model indexes (CFI, TLI, the SRMR and the RMSEA) fall within the acceptable range according to the synthesis of Kline (2015) and Schweizer (2010). As for the $\chi^{2}$, researchers have pointed out that it is very sensitive to sample size and should therefore not be solely relied upon for judging the acceptance or rejection of a structural model (Schermelleh-Engel et al., 2003). It is rather advisable to evaluate model fitness relying on multiple fit indexes as a way to capture the complexity of the model (Schreiber et al., 2006; Fornell \& Larcker, 1981). The standardized total effect of self-esteem on reading motivation is $\beta=.28$, SE $=.097, \mathrm{p}=.002$ istherefore significant. We can confidently say that there is an effect of self-esteem on reading motivation. Unlike 
the reported literature which establishes a theoretical indirect link between self-esteem and the motivation to read (e.g. Harrison, 1994; Baker \& Scher, 2002), the present analysis demonstrates empirically the direct relationship linking both constructs.

Researchers (e.g. Kaniuka, 2010) have conceptualized the relationship between self-esteem and reading motivation as bidirectional. Our research findings show a significant unidirectional link between self-esteem and reading motivation. With the results of this section at hand, we can confirm $\mathrm{H} 2$ hypothesizing the existence of a positive direct effect of self-esteem on reading motivation. Researchers are then called upon to investigate the reciprocal effect between the two constructs in similar and different contexts.

\subsection{Self-esteem and reading motivation among the two sex groups}

With regard to group comparison, an independent t-test was conducted to examine the difference between men and women in self-esteem scores. On average, men reported slightly higher $S E$ results $(M=3.65, S D=0.57)$ than women $(M=3.52, S D=0.54)$. However, the results of the comparison showed no significant statistical difference between the two groups $t(178)=1.44, p=$ .152. Likewise, no significant difference was found in reading motivation scores for men $(M=3.21, S D=0.44)$ and women $(M=3.22$, $\mathrm{SD}=0.45) ; \mathrm{t}(178)=1.51, \mathrm{p}=.122$, despite women reporting marginally higher scores on average than their male counterparts. With regards to self-esteem, in accordance with the literature, the results seem to be consistent in so far as men reported higher self-esteem results compared to women. The difference however is insignificant. Similarly, women reported higher reading motivation, thus joining previous results in the literature (e.g. McGeown et al., 2012; Stutz et al.,2016; Wigfield et al.,2016). In the same context, boys and male adolescents were shown to demonstrate less interest and less reading motivation compared respectively with girls and female adolescents (e.g. Pecjak \& Peklaj, 2006; Wigfield et al., 2016).Unlike the prediction of hypotheses $\mathrm{H} 3$ and $\mathrm{H}_{4}$, and consistent with the existing findings, results indicate the presence of no significant difference between males and females both in self-esteem and in reading motivation.

This leads us to the last part of the study where we summarize our hypothesis-testing results in the following table, which shows that the main hypotheses asserting a positive correlation between self-esteem and motivation ( $\mathrm{H} 1)$ have been confirmed and a direct effect of the former on the latter $(\mathrm{H} 2)$, while the next two hypotheses $(\mathrm{H} 3$ and $\mathrm{H} 4)$ postulating a significant difference between men and women in self-esteem and reading motivation have both been disconfirmed.

\begin{tabular}{|l|c|}
\hline \multicolumn{1}{|c|}{ Hypothesis } & Result \\
\hline (1) There is a positive correlation between self-esteem and reading motivation. & Confirmed \\
\hline (2) There is a significant difference between men and women in reported self-esteem level. & Disconfirmed \\
\hline (3) There is a significant difference between men and women in reported reading motivation scores. & Disconfirmed \\
\hline (4) There is a significant direct effect of self-esteem on reading motivation. & Confirmed \\
\hline
\end{tabular}

\section{Conclusion}

In the present article, we examined primarily the correlational link and the unidirectional effect between self-esteem and reading motivation. Using correlation analysis, results showed a very mild positive relationship between the two constructs. Another equally significant finding is the empirically demonstrable significant direct link between self-esteem and reading motivation through path analysis using a structural model. The next most important finding is the absence of a significant difference between men and women in both self-esteem and reading motivation scores, knowing that the results are in concordance with previous findings reporting a significant difference between the two groups often tipped in the favor of females. This study therefore contributes to the scientific literature in relevant fields by providing evidence in support of the existence of a two-level statistical relationship between self-esteem and reading motivation in a hitherto unexplored Moroccan context. However, before definitive conclusions could be made, more large-scale studies are called upon to investigate further the issue using a larger and more comprehensive sample to permit generalizability to a population level, and other equally instrumental statistical tests to remedy the structural limitations of our investigation.

Funding: This research received no external funding.

Acknowledgments: I would like to thank all students who contributed to data collection through their participation.

Conflicts of Interest: The authors declare no conflict of interest. 


\section{References}

[1] Aarnoutse, C., \& Schellings, G. (2003). Learning reading strategies by triggering reading motivation .Educational Studies, 29(4), 387-409.

[2] Abouserie, R. (1995). Self-esteem and achievement motivation as determinants of students' approaches to studying. Studies in Higher Education, 20(1), 19-26.

[3] Afari, E., Ward, G., \& Khine, M. S. (2012). Global self-esteem and self-efficacy correlates: relation of academic achievement and self-esteem among Emirati students. International Education Studies, 5(2), 49-57.

[4] Al Khatib, S. A. (2012). Exploring the relationship among loneliness, self-esteem, self-efficacy and gender in United Arab Emirates college students. Europe's Journal of Psychology, 8(1), 159-181.

[5] Alves-Martins, M., Peixoto, F., Gouveia-Pereira, M., Amaral, V., \& Pedro, I. (2002). Self-esteem and academic achievement among adolescents. Educational psychology, 22(1), 51-62.

[6] Apriliyanti, R., Warsono, W., \& Mujiyanto, J. (2018). The correlation between interest, motivation, English self-concept and English speaking performance in nursing students. English Education Journal, 8(2), 138-147.

[7] Arens, A. K., \& Jansen, M. (2016). Self-concepts in reading, writing, listening, and speaking: A multidimensional and hierarchical structure and its generalizability across native and foreign languages. Journal of Educational Psychology, 108(5), 646-664.

[8] Baker, L., \& Scher, D. (2002). Beginning readers' motivation for reading in relation to parental beliefs and home reading experiences. Reading Psychology, 23(4), 239-269.

[9] Baker, L., \& Wigfield, A. (1999). Dimensions of children's motivation for reading and their relations to reading activity and reading achievement. Reading Research Quarterly, 34(4), 452-477.

[10] Bagley, C., Bolitho, F., \&Bertrand, L. (1997). Norms and construct validity of the Rosenberg Self-esteem Scale in Canadian high school populations: Implications for counseling. Canadian Journal of Counseling and Psychotherapy, 31(1).82-92.

[11] Baumeister, R. F. (1998). The Self. In D. T. Gilbert, S. T.Fiske, \& G. Lindzey (Eds.).The handbook of social-psychology, Vol. 1(4th ed.). New York: McGraw-Hill.

[12] Baumeister, R. F. (1999a). Self-concept, self-esteem, and identity. In V. J. Derlega, B. A. Winstead, \& W. H. Jones (Eds.), Nelson-Hall Series in Psychology. Personality: Contemporary Theory and Research (p. 339-375). Nelson-Hall Publishers.

[13] Baumeister, R. F. (Ed.). (1999b). The Self in social psychology. Psychology Press.

[14] Baumeister, R. F., Campbell, J. D., Krueger, J. I., \& Vohs, K. D. (2003). Does high self-esteem cause better performance, interpersonal success, happiness, or healthier lifestyles?. Psychological Science in the Public Interest, 4(1), 1-44.

[15] Baumeister, R. F., Campbell, J. D., Krueger, J. I., \& Vohs, K. D. (2005). Exploding the self-esteem myth. Scientific American, $292(1), 84-91$.

[16] Becker, M., McElvany, N., \& Kortenbruck, M. (2010). Intrinsic and extrinsic reading motivation as predictors of reading literacy: a longitudinal study. Journal of Educational Psychology, 102(4), 773-785.

[17] Bentler, P. M. (1990). Comparative fit indexes in structural models. Psychological Bulletin, 107(2), 238-246.

[18] Berkeley, S., Scruggs, T. E., \& Mastropieri, M. A. (2010). Reading comprehension instruction for students with learning disabilities, 19952006: A meta-analysis". Remedial and Special Education, 31(6), 423-436.

[19] Bleidorn, W., Arslan, R. C., Denissen, J. J., Rentfrow, P. J., Gebauer, J. E., Potter, J., \& Gosling, S. D. (2016). Age and gender differences in selfesteem - a cross-cultural window. Journal of Personality and Social Psychology, 111(3), 396-410.

[20] Boonchum, P. (2009). A study of self-identity changes and correlation of influential factors of Thai students studying English. Educational Research and Reviews, 4(11), 535-548.

[21] Booth, M. Z., \& Gerard, J. M. (2011). Self-esteem and academic achievement: a comparative study of adolescent students in England and the United States. Compare: A Journal of Comparative and International Education, 41(5), 629-648.

[22] Brown, H. D. (2006). Principles of language learning and teaching. (5 ${ }^{\text {th }}$ ed.). White Plains, NY: Longman.

[23] Brown, T. A. (2015). Confirmatory factor analysis for applied research. Guilford publications.

[24] Cantor, N., Markus, H., Niedenthal, P., \&Nurius, P. (1986). On motivation and the self-concept".In R. M. Sorrentino \&E. T. Higgins (Eds.), Handbook of motivation and cognition: foundations of social behavior (p. 96-121).Guilford Press.

[25] Carr, M., Borkowski, J. G., \& Maxwell, S. E. (1991). Motivational components of underachievement. Developmental Psychology, 27(1), 108118.

[26] Cast, A. D., \& Burke, P. J. (2002). A theory of self-esteem. Social Forces, 80(3), 1041-1068.

[27] Chen, S. Y. (2007). Extracurricular reading habits of college students in Taiwan: Findings from two national surveys. Journal of Adolescent \& Adult Literacy, 50(8), 642-653.

[28] Chubb, N. H., Fertman, C. I., \& Ross, J. L. (1997). Adolescent self-esteem and locus of control: A longitudinal study of gender and age differences. Adolescence, 32(125), 113-129.

[29] Conradi, K., Jang, B. G., \& McKenna, M. C. (2014). Motivation terminology in reading research: A conceptual review. Educational Psychology Review, 26(1), 127-164.

[30] Coopersmith, S. (1968). Studies in self-esteem. Scientific American, 218(2), 96-107.

[31] Crocker, J., \& Park, L. E. (2004). The costly pursuit of self-esteem. Psychological Bulletin, 130(3), 392-414.

[32] Di Giunta, L., Alessandri, G., Gerbino, M., Kanacri, P. L., Zuffiano, A., \& Caprara, G. V. (2013). The determinants of scholastic achievement: the contribution of personality traits, self-esteem, and academic self-efficacy. Learning and Individual Differences, 27, 102-108.

[33] Dörnyei, Z., Henry, A., \& Maclntyre, P. D. (Eds.). (2014). Motivational dynamics in language learning. Multilingual Matters.

[34] Dörnyei, Z., \& Ryan, S. (2015). The psychology of the language learner revisited. Routledge.

[35] DuBois, D. L., \& Flay, B. R. (2004). The healthy pursuit of self-esteem: Comment on and alternative to the crocker and park (2004) formulation. Psychological Bulletin, 130(3), 415-420.

[36] Echols, L. D., West, R. F., Stanovich, K. E., \&Zehr, K. S. (1996). Using children's literacy activities to predict growth in verbal cognitive skills: A longitudinal investigation. Journal of Educational Psychology, 88(2), 296-304.

[37] Fornell, C., \& Larcker, D. F. (1981). Structural equation models with unobservable variables and measurement error: Algebra and statistics. 
[38] Förster, N., \& Souvignier, E. (2014). Learning progress assessment and goal setting: Effects on reading achievement, reading motivation and reading self-concept. Learning and Instruction, 32, 91-100.

[39] Frijters, J. C., Brown, E., \& Greenberg, D. (2019). Gender differences in the reading motivation of adults with low literacy skills .The Wiley Handbook of Adult Literacy, 63-87.

[40] Gabriel, R., Allington, R., \& Billen, M. (2012). Background knowledge and the magazine reading students choose. Voices from the Middle, 20(1), 52-57.

[41] Gentile, B., Grabe, S., Dolan-Pascoe, B., Twenge, J. M., Wells, B. E., \& Maitino, A. (2009). Gender differences in domain-specific self-esteem: A meta-analysis. Review of General Psychology, 13(1), 34-45.

[42] Guthrie, J. T., Hoa, A. L. W., Wigfield, A., Tonks, S. M., Humenick, N. M., \& Littles, E. (2007). Reading motivation and reading comprehension growth in the later elementary years. Contemporary Educational Psychology, 32(3), 282-313.

[43] Guthrie, J. T., \& Wigfield, A. (1999). How motivation fits into a science of reading. Scientific Studies of Reading, 3(3), 199-205.

[44] Guthrie, J. T., Wigfield, A., Humenick, N. M., Perencevich, K. C., Taboada, A., \& Barbosa, P. (2006). Influences of stimulating tasks on reading motivation and comprehension. The Journal of Educational Research, 99(4), 232-246.

[45] Hair, J. F., Black, W. C., Babin, B. J., Anderson, R. E., \& Tatham, R. L. (1998). Multivariate data analysis (Vol. 5, No. 3, pp. 207-219). Upper Saddle River, NJ: Prentice hall.

[46] Harrison, I. S. (1994). Improve the reading motivation of third-grade children with extra time, encouragement and choice. [S.I.]: Distributed by ERIC Clearinghouse.

[47] Hayati, A. M., \& Ostadian, M. (2008). The relationship between self-esteem and listening comprehension of EFL students. Published Research, Faculty of Letters and Humanities, Shahid Chamran University of Ahvaz, Iran, 1-13.

[48] Hebbecker, K., Förster, N.,\& Souvignier, E. (2019). Reciprocal effects between reading achievement and intrinsic and extrinsic reading motivation. Scientific Studies of Reading, 23(5), 419-436.

[49] Heyde, A. (1979). The relationship between self-esteem and the oral production of an L2.Unpublished Doctoral Dissertation, The University of Michigan, Ann Arbor, Michigan.

[50] Hisken, L. J. (2011). The correlation between self-esteem and student reading ability, reading level, and academic achievement. University of Central Missouri.

[51] Huang, S., Capps, M., Blacklock, J., \& Garza, M. (2014). Reading habits of college students in the United States. Reading Psychology, 35(5), 437-467.

[52] Kammann, R. A. (1963). Aptitude, study habits, and reading improvement. Journal of Developmental Reading, 6(2), 77-86.

[53] Kaniuka, T. S. (2010). Reading achievement, attitude toward reading, and reading self-esteem of historically low achieving students. Journal of Instructional Psychology, 37(2), 184-188.

[54] Kline, R. B. (2015). Principles and practice of structural equation modeling (4th ed.). New York, NY: The Guilford Press.

[55] Kling, K. C., Hyde, J. S., Showers, C. J., \& Buswell, B. N. (1999). Gender differences in self-esteem: A meta-analysis. Psychological Bulletin, 125(4), 470-500.

[56] Kush, J. C., \& Watkins, M. W. (1996). Long-term stability of children's attitudes toward reading. The Journal of Educational Research, 89(5), 315-319.

[57] Lane, J., Lane, A. M., \& Kyprianou, A. (2004). Self-efficacy, self-esteem and their impact on academic performance. Social Behavior and Personality: An International Journal, 32(3), 247-256.

[58] Lawrence, D. (1981). The development of a self-esteem questionnaire. British Journal of Educational Psychology, 51(2), $245-251$.

[59] Leppänen, U., Aunola, K., \& Nurmi, J. E. (2005). Beginning readers' reading performance and reading habits. Journal of Research in Reading, 28(4), 383-399.

[60] Leys, C., Delacre, M., Mora, Y. L., Lakens, D., \& Ley,C. (2019). How to classify, detect, and manage univariate and multivariate outliers, with emphasis on pre-registration. International Review of Social Psychology, 32(1).

[61] Maqsud, M. (1983). Relationships of locus of control to self-esteem, academic achievement, and prediction of performance among Nigerian secondary school pupils. British Journal of Educational Psychology, 53(2), 215-221.

[62] Martín-Albo, J., Núñez, J. L., Navarro, J. G., \& Grijalvo, F. (2007). The Rosenberg Self-esteem Scale: Translation and validation in university students. The Spanish Journal of Psychology, 10(2), 458-467.

[63] McGeown, S. P. (2015). Sex or gender identity? Understanding children's reading choices and motivation. Journal of Research in Reading, $38(1), 35-46$.

[64] McGeown, S. P., Duncan, L. G., Griffiths, Y. M., \& Stothard, S. E. (2015). Exploring the relationship between adolescent's reading skills, reading motivation and reading habits. Reading and Writing, 28(4), 545-569.

[65] McGeown, S., Goodwin, H., Henderson, N., \& Wright, P. (2012). Gender differences in reading motivation: Does sex or gender identity provide a better account?. Journal of Research in Reading, 35(3), 328-336.

[66] McGeown, S. P., Norgate, R., \&Warhurst, A. (2012). Exploring intrinsic and extrinsic reading motivation among very good and very poor readers. Educational Research, 54(3), 309-322.

[67] McMullin, J. A., \& Cairney, J. (2004). Self-esteem and the intersection of age, class, and gender. Journal of Aging Studies, 18(1), 75-90.

[68] Merisuo-Storm, T. (2006). Girls and boys like to read and write different texts. Scandinavian Journal of Educational Research, 50(2), 111-125.

[69] Pecjak, S., \& Peklaj, C. (2006). Dimensions of reading motivation and reading achievement in 3rd and 7th grade students. Studia Psychologica, 48(1), 11-29.

[70] Robins, R. W., Hendin, H. M., \& Trzesniewski, K. H. (2001). Measuring global self-esteem: Construct validation of a single-item measure and the Rosenberg Self-esteem Scale. Personality and Social Psychology Bulletin,27(2), 151-161.

[71] Robins, R. W., Tracy, J. L., Trzesniewski, K., Potter, J., \& Gosling, S. D. (2001). Personality correlates of self-esteem. Journal of Research in Personality, 35(4), 463-482.

[72] Robson, P. (1989). Development of a new self-report questionnaire to measure self-esteem. Psychological Medicine, 19(2), 513-518.

[73] Rosenberg, M. (1965). Society and the adolescent self-image. Princeton, NJ: Princeton University Press. 
[74] Rubio, F. D. (2014). Self-esteem and self-concept in foreign language learning. In Mercer, S., \& Williams, M. (Eds.). (2014). Multiple perspectives on the self in SLA (p. 41-58.).Multilingual Matters.

[75] Scheier, M. F., Carver, C. S., \& Bridges, M. W. (1994). Distinguishing optimism from neuroticism (and trait anxiety, self-mastery, and selfesteem): A reevaluation of the life orientation test. Journal of Personality and Social Psychology, 67(6), 10-63.

[76] Schermelleh-Engel, K., Moosbrugger, H., \& Müller, H. (2003). Evaluating the fit of structural equation models: tests of significance and descriptive goodness-of-fit measures. Methods of Psychological Research Online, 8(2), 23-74.

[77] Schiefele, U., Schaffner, E., Möller, J., \& Wigfield, A. (2012). Dimensions of reading motivation and their relation to reading behavior and competence. Reading Research Quarterly, 47(4), 427-463.

[78] Schreiber, J. B., Nora, A., Stage, F. K., Barlow, E. A., \& King, J. (2006). Reporting structural equation modeling and confirmatory factor analysis results: A review. The Journal of Educational Research, 99(6), 323-338.

[79] Schutte, N. S., \& Malouff, J. M. (2007). Dimensions of reading motivation: Development of an adult reading motivation scale. Reading Psychology, 28(5), 469-489.

[80] Schwabe, F., McElvany, N., \&Trendtel, M. (2015). The school age gender gap in reading achievement: Examining the influences of item format and intrinsic reading motivation. Reading Research Quarterly, 50(2), 219-232.

[81] Schweizer, K. (2010). Some guidelines concerning the modeling of traits and abilities in test construction". European Journal of Psychological Assessment,26(1), 1-2.

[82] Shankar, P. R., Dubey, A. K., Mishra, P., \&Upadhyay, D. K. (2008). Reading habits and attitude toward medical humanities of basic science students in a medical college in western Nepal. Teaching and Learning in Medicine, 20(4), 308-313.

[83] Simpson, C. K., \& Boyle, D. (1975). Esteem construct generality and academic performance. Educational and Psychological Measurement, 35(4), 897-904.

[84] Soufi, S., Damirchi, E. S., Sedghi, N., \& Sabayan, B. (2014). Development of structural model for prediction of academic achievement by global self-esteem, academic self-concept, self-regulated learning strategies and autonomous academic motivation. Procedia - Social and Behavioral Sciences, 114, 26-35.

[85] Soureshjani, K. H., \& Naseri, N. (2011). An investigation into the relationship between self-esteem, proficiency level, and the reading ability of Iranian EFL language learners. Journal of Language Teaching and Research, 2(6), 1312-1319.

[86] Srivastava, R., \& Joshi, S. (2014). Relationship between self-concept and self-esteem in adolescents. International Journal of Advanced Research, 2(2), 36-43.

[87] Stein, J. A., Newcomb, M. D., \& Bentler, P. M. (1992). The effect of agency and communality on self-esteem: gender differences in longitudinal data. Sex Roles, 26(11-12), 465-483.

[88] Stutz, F., Schaffner, E., \& Schiefele, U. (2016). Relations among reading motivation, reading amount, and reading comprehension in the early elementary grades. Learning and Individual Differences, 45, 101-113.

[89] Swann Jr, W. B., Chang-Schneider, C., \& Larsen McClarty, K. (2007). Do people's self-views matter? Self-concept and self-esteem in everyday life. American Psychologist, 62(2), 84-94.

[90] Tabachnick, B. G., \& Fidell, L. S. (2013).Using multivariate statistics (6th Ed.). Boston, MA: Pearson.

[91] Trautwein, U., Lüdtke, O., Köller, O., \& Baumert, J. (2006). Self-esteem, academic self-concept, and achievement: How the learning environment moderates the dynamics of self-concept". Journal of Personality and Social Psychology, 90(2), 334-349.

[92] Tucker, L. R., \& Lewis, C. (1973). A reliability coefficient for maximum likelihood factor analysis". Psychometrika, 38(1), 1-10.

[93] Twist, L., Gnaldi, M., Schagen, I., \& Morrison, J. (2004). Good readers but at a cost? Attitudes to reading in England. Journal of Research in Reading, 27(4), 387-400.

[94] Unrau, N. J., \& Quirk, M. (2014). Reading motivation and reading engagement: Clarifying commingled conceptions. Reading Psychology, 35(3), 260-284.

[95] Van Lier, L. (2010). Forward: Agency, self and identity in language learning. In O'Rourke, B., \& Carson, L. (2010). Language learner Autonomy: Policy, curriculum, classroom (p. 5-14). Bern, Switzerland: Peter Lang UK.

[96] Wang, J. H. Y., \& Guthrie, J. T. (2004). Modeling the effects of intrinsic motivation, extrinsic motivation, amount of reading, and past reading achievement on text comprehension between US and Chinese students. Reading Research Quarterly, 39(2), 162-186.

[97] Watkins, M. W., \& Coffey, D. Y. (2004). Reading motivation: Multidimensional and indeterminate. Journal of Educational Psychology, 96(1), 110-118.

[98] Wigfield, A. (1997). "Reading motivation: A domain-specific approach to motivation. Educational psychologist, 32(2), 59-68.

[99] Wigfield, A., Gladstone, J. R., \& Turci, L. (2016). Beyond cognition: Reading motivation and reading comprehension. Child Development Perspectives, 10(3), 190-195.

Zaff, J. F., \& Hair, E. C. (2003). Positive development of the self: Self-concept, self-esteem, and identity. In M. H. Bornstein, L. Davidson, C. L. M. Keyes, \& K. A. Moore (Eds.), Crosscurrents in contemporary psychology. Well-being: Positive development across the life course (p. 235-251). Lawrence Erlbaum Associates Publishers. 